\title{
In vitro toxicity studies of biodegradable, polyelectrolyte nanocapsules
}

This article was published in the following Dove Press journal:

International Journal of Nanomedicine

\author{
Alicja Karabasz' \\ Krzysztof Szczepanowicz ${ }^{2}$ \\ Agnieszka Cierniak ${ }^{1,3}$ \\ Joanna Bereta' \\ Monika Bzowska' \\ 'Department of Cell Biochemistry, \\ Faculty of Biochemistry, Biophysics \\ and Biotechnology, Jagiellonian \\ University, Kraków, Poland; ${ }^{2}$ Jerzy \\ Haber Institute of Catalysis and \\ Surface Chemistry, Polish Academy \\ of Sciences, Kraków, Poland; \\ ${ }^{3}$ Department of Biochemistry, Faculty \\ of Medicine and Health Sciences, \\ Andrzej Frycz Modrzewski Kraków \\ University, Kraków, Poland
}

\begin{abstract}
Background: Toxicity of nanomaterials is one of the most important factors limiting their medical application. Evaluation of in vitro nanotoxicity allows for the identification and elimination of most of the toxic materials prior to animal testing. The current knowledge of the possible side effects of biodegradable nanomaterials, such as liposomes and polymeric organic nanoparticles, is limited. Previously, we developed a potential drug delivery system in the form of nanocapsules with polyelectrolyte, biodegradable shells consisting of poly-L-lysine and poly-L-glutamic acid (PGA), formed by the layer-by-layer adsorption technique.
\end{abstract}

Methods: Hemolysis assay, viability tests, flow cytometry analysis of vascular cell adhesion molecule-1 expression on endothelium, analysis of nitric oxide production, measurement of intracellular reactive oxygen species levels, detection of antioxidant enzyme activity, and analysis of DNA damage with comet assay were performed to study the in vitro toxicity of nanocapsules.

Results: In this work, we present the results of an in vitro analysis of toxicity of five-layer positively charged poly-L-lysine-terminated nanocapsules (NC5), six-layer negatively charged PGA-terminated nanocapsules (NC6) and five-layer PEGylated nanocapsules (NC5-PEG). PGA and polyethylene glycol (PEG) were used as two different "stealth" polymers. Of all the polyelectrolyte nanocapsules tested for blood compatibility, only cationic NC5 showed acute toxicity toward blood cells, expressed as hemolysis and aggregation. Neither NC6 nor NC5-PEG had proinflammatory activity evaluated through changes in the expression of NF- $\mathrm{KB}$-dependent genes, iNOS and vascular cell adhesion molecule-1, induced oxidative stress, or promoted DNA damage in various cells.

Conclusion: Our studies clearly indicate that PGA-coated (negatively charged) and PEGylated polyelectrolyte nanocapsules do not show in vitro toxicity, and their potential as a drug delivery system may be safely studied in vivo.

Keywords: polyelectrolyte nanocapsules, layer-by-layer, nanotoxicity, oxidative stress, genotoxicity

\section{Introduction}

Nanotechnology is a broad and rapidly growing field of materials science that is revolutionizing industry, research and medicine. One of its branches, nanodiagnostics, utilizes quantum dots or semiconductor nanocrystals for cell labeling and for imaging purposes. ${ }^{1,2}$ Various nanomaterials have gained attention as non-viral delivery systems for gene therapy. ${ }^{3}$ Finally, nanopharmacology offers novel solutions for vaccine or drug formulations to improve their bioavailability, biodistribution and pharmacokinetic stability, while reducing their toxicity against healthy tissues. Despite the enormous contribution to the development of nanomaterials for medical applications, the number of nanotherapies approved by the US Food and Drug Administration is still low. ${ }^{4}$ The most
Correspondence: Monika Bzowska Department of Cell Biochemistry, Faculty of Biochemistry, Biophysics and Biotechnology, Jagiellonian University, Kraków, 7 Gronostajowa St, 30-387 Kraków, Poland

Tel/fax +48 I2 6646388

Email monika.bzowska@uj.edu.pl
International Journal of Nanomedicine 2018:13 5159-5172

5159

Dovepress if in 0

http://dx.doi.org/10.2147/IJN.SI69120 (c) (7) (5) 2018 Karabasz et al. This work is published and licensed by Dove Medical Press Limited. The full terms of this license are available at https://www.dovepress.com/terms.php cc) and incorporate the Creative Commons Attribution - Non Commercial (unported, v3.0) License (http://creativecommons.org//icenses/by-nc/3.0/). By accessing the work you hereby accept the Terms. Non-commercial uses of the work are permitted without any further permission from Dove Medical Press Limited, provided the work is properly attributed. For permission for commercial use of this work, please see paragraphs 4.2 and 5 of our Terms (https://www.dovepress.com/terms.php). 
important factor that hampers the therapeutic use of many nanomaterials is their own acute and chronic toxicity. The acute effects may be manifested by hemolysis of erythrocytes, aggregation of platelets or leukocytes, triggering coagulation cascade and decreasing the viability of various normal cells. Chronic effects comprise, among others, the inflammatory and antigenic response, oxidative stress and DNA damage that may finally cause allergy, cardiovascular diseases or cancer. ${ }^{5}$ In recent years, more research has been focused on the development of biodegradable organic nanomaterials that are degraded in the body to the cell building blocks such as sugars, amino acids, fatty acids or nucleotides. ${ }^{6}$ Biodegradable nanomaterials are implicitly assumed to be nontoxic, and much less attention is paid to their potential side effects than to those of inorganic ones. However, the detailed toxicity studies should comprise all nanomaterials designed for therapies because nanotoxicity results not only from the chemical composition of a nanoparticle, but also from its physical properties including size, shape, charge, as well as surface decoration. ${ }^{7}$

The functionalization of a nanoparticle surface with hydrophilic polymers is an approach for extending nanomaterial circulating lifetime, enhancing its delivery and retention in the target tissues, and decreasing its systemic toxicity. The improvement of the pharmacokinetic profile observed after surface decoration is primarily due to diminished nanomaterial aggregation and interactions with serum opsonins, which accelerate nanoparticle phagocytosis by monocytes and macrophages. Additionally, lower systemic toxicity of modified nanoparticles may be a consequence of their weaker interactions with red blood cells (RBCs) and decreased level of hemolysis. Currently, polyethylene glycol (PEG) is the polymer most often used for nanomaterial functionalization. Alternative strategies replacing PEG with poly-amino acids, for example, poly-L-glutamic acid (PGA), have been also recently implemented. ${ }^{8}$

One of the most promising methods of nanocarrier formation is the layer-by-layer ( $\mathrm{LbL}$ ) technique originally proposed by Sukhorukov et al and based on sequential, alternate adsorption of positively and negatively charged nano-objects on a colloidal core. ${ }^{9}$ This strategy allows forming polyelectrolyte nanocarriers containing active compounds, for example, drugs. In recent years, various polyelectrolyte nanoparticles composed of, for example, chitosan, poly(2-acrylamido-2-methylpropanesulfonic acid), poly-L-lysine (PLL) and poly(ethylene glycol)-poly(Llysine)-poly(lactic acid), have been explored as promising carriers for the delivery of anticancer compounds, such as curcumin, ${ }^{10}$ doxorubicin ${ }^{11}$ or camptothecin, ${ }^{12}$ as well as photosensitizers for photodynamic therapy. ${ }^{13}$

Our previous studies pointed to the polyelectrolyte nanocapsules formed by encapsulation of nanoemulsion droplets in multilayer shells of poly-amino acids, namely PLL and PGA, as a promising candidate for a drug delivery system. We characterized nanoparticles similar in size, but differing in charge and surface decoration with PEG and found that both negatively charged as well as close to neutral, PEGylated empty polyelectrolyte nanocapsules did not affect the viability of various cell types. However, drugs encapsulated in those nanomaterials possessed biological activity comparable to or better than the carrier-free drug formulations. ${ }^{14,15}$ Moreover, using confocal microscopy we demonstrated that fluorescently labeled non-PEGylated and PEGylated nanocapsules are internalized by different cells, with most of the internalized nanocapsules taken up by the lysosomes. ${ }^{14,16,17}$

Here, we present the results of in vitro studies of PLLterminated, PGA-terminated and PEGylated, five to six layer polyelectrolyte nanocapsules which were performed to predict their potential in vivo toxicity after intended intravenous administration. Two out of three tested nanocapsules, namely PGA-terminated six-polyelectrolyte layer nanocapsules (NC6); PEGylated five-polyelectrolyte layer nanocapsules (NC5-PEG), passed all in vitro tests, showing no undesired effects, which indicates the validity of their further in vivo evaluation.

\section{Materials and methods Chemicals for polyelectrolyte} nanocapsules synthesis

All purchased reagents were used without any further purification. The polyelectrolytes, PLL hydrobromide, PLL (MW 15,000-30,000), PGA sodium salt, PGA (MW 15,000-50,000), surfactant, the solvent docusate sodium salt (AOT), and chloroform, as well as sodium chloride were obtained from Sigma-Aldrich. PEGylated polyelectrolyte poly(L-lysine)-graft-poly(ethylene glycol) PLL (20,000)-g-PEG (5,000) was purchased from SuSoS (Dübendorf, Switzerland). Ultrapure water was obtained using the Millipore Direct-Q5 UV purification system.

\section{Materials for biological analysis}

All reagents for cell culture were obtained from Lonza. Ficoll-Paque Plus used for peripheral blood mononuclear cell (PBMC) isolation was provided by GE Healthcare. MTT, lipopolysaccharide (LPS), sulphanilic acid, $N$-(1-naphtyl) 
ethylenediaminedihydrochloride, $2^{\prime} 7^{\prime}$-dichlorofluorescin diacetate (DCFH-DA) nitroblue tetrazolium, riboflavin, etoposide, Drabkin's reagent, BRIJ ${ }^{\circledR}$ L23 solution, bovine hemoglobin, Dulbecco's PBS (DPBS), $N, N, N^{\prime}, N^{\prime}$-tetramethylethylenediamine and phorbol 12-myristate 13-acetate (PMA) were purchased from Sigma-Aldrich. Mouse interferon $\gamma($ IFN- $\gamma)$ was obtained from R\&D Systems. Homemade recombinant human tumor necrosis factor (TNF) was purified from the culture media of mouse fibroblasts stably expressing TNF by affinity chromatography on anti-TNF monoclonal antibody conjugated to Sepharose. Biological activity of TNF was standardized using human TNF provided by Sigma-Aldrich. Lack of LPS contamination was verified with E-TOXATE kit (Sigma-Aldrich).

\section{Nanocapsules preparation}

Multilayer polyelectrolyte nanocarriers, NC5 (PLL-terminated five-polyelectrolyte layer nanocapsules), NC6 (PGA-terminated six-polyelectrolyte layer nanocapsules) and NC5-PEG (PEGylated five-polyelectrolyte layer nanocapsules), were synthesized by the method developed previously. ${ }^{18}$ Nanoemulsion droplets were formed by dispersing $0.1 \mathrm{~mL}$ of oil phase (chloroform containing AOT $34 \mathrm{mg} / \mathrm{mL}$ ) into $200 \mathrm{~mL}$ aqueous phase (polycation solution PLL $0.1 \mathrm{mg} / \mathrm{mL}, 15 \mathrm{mM} \mathrm{NaCl}$ ). Subsequently, the formed nanoemulsion droplets were encapsulated in polyelectrolyte multilayer shell using the LbL technique with saturation approach as described in detail previously. The volumes of polyelectrolytes used for the formation of consecutive layers of the multilayer shell were as follows: $1 \mathrm{~mL}$ PGA, 1.3 mL PLL, 1.5 mL PGA, 3 mL PLL, 3.5 mL PGA (all polyelectrolytes at the concentration $2 \mathrm{mg} / \mathrm{mL}$ ). To form PEGylated nanocapsules, PGA-terminated four-layer nanocapsules were coated with a layer of PLL-g-PEG using the same procedure as for normal polyelectrolyte. ${ }^{14}$ Chloroform was evaporated under reduced pressure and its final concentration measured by gas chromatography with an electron capture detector was $\sim 0.04 \mathrm{mg} / \mathrm{L} .{ }^{16}$ The stability of nanocapsules was evaluated by the periodic measurements of their size and zeta potential.

\section{Nanocapsules characterization}

The size distribution was determined by dynamic light scattering, while the zeta potential was determined by Laser Doppler Electrophoresis, both using Zetasizer Nano Series from Malvern Instruments. The nanocapsules concentration was determined by Nanoparticle Tracking Analysis using NanoSight NS500 (Malvern Instruments). The obtained values were an average of at least three measurements. All measurements were performed at $25^{\circ} \mathrm{C}$ in $15 \mathrm{mM} \mathrm{NaCl}$.
Nanocapsules were also visualized by Cryo-Scanning Electron Microscopy using Jeol JSM 7600F field emission scanning electron microscope FESEM (Jeol Ltd, Tokyo, Japan) according to the protocol described previously. ${ }^{14}$

\section{Cells, cell cultures and the concentration of nanocapsules}

Human hepatoma-derived HepG2 cell line (ATCC $\left.{ }^{\circledR} \mathrm{HB}-8065\right)$ and mouse macrophage cell line P388D1 (ATCC ${ }^{\circledR}$ CCL-46) were obtained from American Type Culture Collection. Murine brain endothelial MBE cells were a gift from R Auerbach (University of Wisconsin, Madison, WI, USA). Their use was approved by the Animal Welfare Committee at the Faculty of Biochemistry, Biophysics and Biotechnology, Jagiellonian University, pursuant to the Polish and European legal acts. Citrated human blood from healthy volunteers was purchased from the Regional Center of Blood Donation and Treatment in Kraków, Poland. Regional Center of Blood Donation and Treatment deidentified blood materials as appropriate for the confidentiality assurance of human subjects. Thus, this study adheres to appropriate exclusions from the approval of human subjects.

All cells were cultivated in an incubator $\left(5 \% \mathrm{CO}_{2}\right.$, $37^{\circ} \mathrm{C},>95 \%$ humidity). The final concentration of nanocapsules used in all biological experiments was $\sim 2 \times 10^{11} / \mathrm{mL}$. From our previous studies, it is clear that this concentration of nanocapsules is necessary to deliver a closed drug in amounts comparable to those applied as nanocarrier-free formulations. ${ }^{14,19}$

\section{Hemolytic activity of polyelectrolyte nanocapsules}

Analysis of the hemolysis of human erythrocytes was performed according to the procedure proposed by Dobrovolskaia et al. ${ }^{20}$ Plasma-free hemoglobin and total blood hemoglobin (TBH) were measured spectrophotometrically at $540 \mathrm{~nm}$ using a microplate reader after reaction with cyanmethemoglobin reagent (Drabkin's reagent). Next, the entire blood samples were diluted with DPBS to adjust the total hemoglobin concentration to $10 \mathrm{mg} / \mathrm{mL}$ (diluted TBH [dTBH]). Aliquots of $0.1 \mathrm{~mL}$ of erythrocyte suspensions (dTBH) were mixed with $0.8 \mathrm{~mL}$ of DPBS and with 1) $0.1 \mathrm{~mL}$ of $15 \mathrm{mM} \mathrm{NaCl}$ (hemolysis of untreated RBC), or 2) $0.1 \mathrm{~mL}$ of Triton X-100 ( $4 \% \mathrm{v} / \mathrm{v}$, positive control of hemolysis), or 3) $0.1 \mathrm{~mL}$ of NC5 nanocapsules, or 4) $0.1 \mathrm{~mL}$ of NC6 or 5) $0.1 \mathrm{~mL}$ of NC5-PEG, and incubated at $37^{\circ} \mathrm{C}$ for 3 hours with gentle shaking. Erythrocyte morphology was analyzed using inverted light microscope LeicaDM IL LED Fluo. The cells were centrifuged $(1,500 \times g, 5$ minutes) and 
the concentration of the released hemoglobin was determined (defined as "sample" in the following formula). The level of hemolysis was calculated as follows:

$$
\% \text { hemolysis }=\frac{[\mathrm{Hb}] \mathrm{sample}}{[\mathrm{Hb}] \mathrm{dTBH}} \times 100 \%
$$

\section{Cytotoxicity assay for PBMCs}

Human PBMCs were isolated from the blood of different healthy donors using Ficoll-Paque Plus gradient fractionation according to the manufacturer's protocol and stored at $-80^{\circ} \mathrm{C}$ in fetal bovine serum (FBS) containing $10 \%$ dimethyl sulfoxide. Prior to experiments, thawed PBMCs were cultivated in 96-well plates at a density of $1 \times 10^{5} /$ well in $100 \mu \mathrm{L}$ of growth medium (RPMI supplemented with antibiotics [100 U/mL penicillin, $100 \mu \mathrm{g} / \mathrm{mL}$ streptomycin] and 20\% FBS). The next day, the medium was replaced with fresh growth medium containing additionally: 1) $1.5 \mathrm{mM}$ $\mathrm{NaCl}, 2$ ) NC5, 3) NC6 and 4) NC5-PEG. After 48 hours, the viability of PBMCs was estimated by the trypan blue dye exclusion test. All cells and dead cells were counted in Bürker's chamber. The percentage of the dead cells was calculated according to the formula:

$$
\% \text { dead cell }=\frac{\text { Dead cell number }}{\text { Total cell number }} \times 100 \%
$$

Morphological changes were analyzed using the inverted light microscope LeicaDM IL LED Fluo.

\section{MTT assay}

P388D1 and MBE cells were grown in DMEM (4.5 g glucose/L), while HepG2 cells were grown in DMEM (1 g glucose/L); both media contained $10 \%$ FBS and antibiotics. For experiments, the cells were seeded on 96-well plates in $100 \mu \mathrm{L}$ of growth medium (density of $5 \times 10^{3} /$ well for P388D 1 and HepG2, and $2 \times 10^{4} /$ well for MBE). After 48 hours, the media were replaced with fresh ones containing 1) $1.5 \mathrm{mM}$ $\mathrm{NaCl}, 2$ ) NC5, 3) NC6 and 4) NC5-PEG. After 48 hours, the cell morphology was examined and the viability of the cells was determined by MTT assay according to the standard protocol. ${ }^{21}$ Cell viability was calculated using the following formula (where A545 is absorbance measured at $545 \mathrm{~nm}$.):

$$
\text { Cell viability }(\% \text { control })=\frac{\mathrm{A}_{545}(\text { sample })}{\mathrm{A}_{545}(\text { untreated cells })} \times 100 \%
$$

\section{Analysis of the influence of the nanocapsules on nitric oxide (NO) production}

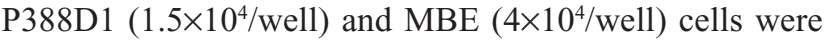
grown in 96-well plates in DMEM supplemented with 5\% FBS and antibiotics. The next day, the medium was replaced with DMEM supplemented with $2 \%$ FBS and antibiotics, and in order to stimulate inducible nitric oxide synthase (iNOS) expression, it was replaced with LPS and/or cytokines. In the case of P388D1, the groups contained 1) $1.5 \mathrm{mM} \mathrm{NaCl}$, 2) NC6, 3) NC5-PEG, 4) LPS (100 ng/mL), 5) LPS+NC6, 6) LPS+NC5-PEG, 7) IFN- $\gamma(10 \mathrm{ng} / \mathrm{mL})$, 8) IFN- $\gamma+\mathrm{NC} 6$, 9) IFN- $\gamma+\mathrm{NC} 5-\mathrm{PEG}$, 10) LPS+IFN- $\gamma$, 11) LPS+IFN- $\gamma+\mathrm{NC} 6$ and 12) LPS+IFN- $\gamma+N C 5-P E G$. For MBE cells, the same scheme was applied except that TNF $(10 \mathrm{ng} / \mathrm{mL})$ was used instead of LPS. The nitrite levels in the culture media $(100 \mu \mathrm{L})$ were measured after 24 hours using $100 \mu \mathrm{L}$ of Griess reagent $(1 \%[\mathrm{w} / \mathrm{v}]$ sulfanilic acid $/ 0.1 \%[\mathrm{w} / \mathrm{v}]$ $\mathrm{N}$-(1-naphtyl) ethylenediaminedihydrochloride [Sigma] in $\left.2.5 \%[\mathrm{v} / \mathrm{v}] \mathrm{H}_{3} \mathrm{PO}_{4}\right)$. The absorbance was measured at $545 \mathrm{~nm}$ using a microplate reader (Versa Max, SoftMaxPro; Molecular Devices).

\section{Analysis of vascular cell adhesion molecule-I (VCAM-I) expression}

MBE cells were grown in 12 -well plate $\left(2 \times 10^{5}\right.$ cells/well $)$ in DMEM enriched with $10 \%$ FBS and antibiotics. The next day, the cells were incubated for 24 hours in DMEM containing 2\% FBS, and TNF $(10 \mathrm{ng} / \mathrm{mL})$ or NC6 or NC5-PEG. Then the cells were washed with PBS, detached from plates with accutase and stained with phycoerythrin (PE)-conjugated rat anti-VCAM-1 IgG according to the protocol provided by the antibody supplier (Pharmingen, PE Rat-Anti-Mouse CD106 Clone 429; BD Biosciences). VCAM-1 expression was analyzed by flow cytometry using BD FACSCalibur flow cytometer and CellQuestPro software (Becton Dickinson).

\section{Detection of reactive oxygen species}

The amount of reactive oxygen species (ROS) was measured using the DCFH-DA assay. HepG2 cells were seeded at $1.5 \times 10^{4}$ cells $/$ well in a $96-$ well sterile plate with transparent and flat bottom for fluorescent assay in $100 \mu \mathrm{L}$ of growth medium. The next day, the medium was replaced with fresh growth medium containing 1) $1.5 \mathrm{mM} \mathrm{NaCl}$, 2) $\mathrm{NC} 6$ and 3) NC5-PEG, and the cells were incubated for the next 2 , 6 or 24 hours. After removal of the medium, staining with $25 \mu \mathrm{M}$ DCFH-DA in PBS was performed for 30 minutes 
(in dark, room temperature [RT]), followed by addition of $100 \mu \mathrm{L}$ of $1 \mathrm{mM} \mathrm{H}_{2} \mathrm{O}_{2}$ in PBS to half of the wells for another 30 minutes (RT, in dark). The staining solution was discarded, cells were washed once with PBS and $100 \mu \mathrm{L}$ of PBS was added to each well. Fluorescent area scan reading (number of points horizontal $\times$ vertical $=5 \times 5$, excitation $470 \mathrm{~nm}$, emission $535 \mathrm{~nm}$ ) was performed using Synergy H1 hybrid reader and analyzed with Gene5 Software (BIOTEK Instruments). A mean fluorescence intensity of $100 \%$ corresponds to fluorescence intensity measured for HepG2 incubated with $\mathrm{NaCl}$ prior to DCFH staining.

\section{Analysis of superoxide dismutase (SOD) activity}

HepG2 cells were grown overnight in a 12-well plate ( $2 \times 10^{5}$ cells/well, in $1 \mathrm{~mL}$ of growth medium). Prior to the experiment, the medium was replaced with a fresh one containing 1) $1.5 \mathrm{mM} \mathrm{NaCl}, 2$ ) NC6, 3) NC5-PEG and 4) PMA (100 ng/mL, positive control). After 24 hours, HepG2 cells were trypsinized, resuspended in $25 \mu \mathrm{L}$ of PBS, subjected to repeated freeze-thaw cycles to release cellular proteins and centrifuged. The extracted proteins $(5 \mu \mathrm{g})$ were separated on $12 \%$ polyacrylamide gel (native conditions, 1.5 hours, $20 \mathrm{~V} /$ $\mathrm{cm}$, room temperature [RT]). The gels were stained for 20 minutes at RT in staining solution ( $50 \mathrm{mM}$ phosphate buffer pH 7.4, $10 \mathrm{mM}$ EDTA, $0.25 \mathrm{mM}$ nitroblue tetrazolium, $28 \mathrm{mM}$ $N, N, N^{\prime}, N^{\prime}$-tetramethylethylenediamine and $30 \mu \mathrm{M}$ riboflavin). Gel analysis was performed with Fusion $\mathrm{F} \times 5$ (Vilber).

\section{Comet assay}

DNA damage was measured by electrophoretic fractionation of single cells in agarose gel. P388D1 $\left(4 \times 10^{4}\right.$ cells/well), PBMC $\left(1 \times 10^{5}\right.$ cells/well $)$ and HepG2 $\left(8 \times 10^{4}\right.$ cells/well $)$ cells were incubated for 2,24 or 48 hours with $1.5 \mathrm{mM}$ $\mathrm{NaCl}$ or with different nanocapsules: NC6 or NC5-PEG. Etoposide was used as a DNA damage inducer $(25 \mu \mathrm{M}$ for PBMC, $10 \mu \mathrm{M}$ for HepG2 and $1 \mu \mathrm{M}$ for P388D1). After incubation, the cells were collected from plates and mixed with low-melting-point agarose $\left(0.1 \%\right.$ agarose, $\left.37^{\circ} \mathrm{C}\right)$. Then, 10,000 cells in $100 \mu \mathrm{L}$ of agarose were smeared on slides precoated with a layer of $1 \%$ normal melting point agarose. Cells were lysed, DNA was alkali denatured and subjected to electrophoresis $(0.74 \mathrm{~V} / \mathrm{cm}, 300 \mathrm{~mA})$ for 30 minutes at $4^{\circ} \mathrm{C}$ in $300 \mathrm{mM} \mathrm{NaOH}, 1 \mathrm{mM}$ EDTA buffer and analyzed as described by Kyzioł et al. ${ }^{22}$ The percentage of DNA in the tail (\% DNA damage) was determined from two slides per sample with 50 randomly selected cells per slide.

\section{Statistical analysis}

Statistical significance was analyzed by the Mann-Whitney U test using Origin 2018 Pro software, with $P<0.05$ being considered significant. Bars represent the mean \pm SD from at least three independent experiments performed using nanomaterials from two different syntheses.

\section{Results \\ Synthesis and characterization of polyelectrolyte nanocapsules}

Nanoemulsion droplets (size $\sim 100 \mathrm{~nm}$ and polydispersity index $<0.2$; Figure $1 \mathrm{~A}$ ) stabilized by the surfactant/ polyelectrolyte (AOT/PLL) interfacial complex that provides favorable condition for nanoemulsification and simultaneously stable surface charge for polyelectrolyte adsorption ${ }^{23}$ were formed according to the procedure described in the previous section. The zeta potential of formed droplets was high enough $(+64 \mathrm{mV})$ to provide sufficient electric stabilization against their aggregation. Polyelectrolyte (PGA, PLL and PLL-g-PEG) multilayer shells were constructed by the LbL approach on the nanodroplets formed. The adsorption of consecutive PGA and PLL layers resulted in changes in zeta potential values arranged in the typical saw-like pattern (average zeta potential: $+40 \mathrm{mV}$ for $\mathrm{NC} 5$ and $-40 \mathrm{mV}$ for NC6), while the adsorption of PEGylated polyelectrolyte (PLL-g-PEG) decreased the zeta potential to values close to zero $(4 \pm 5 \mathrm{mV})$, as shown in Figure 1B. The average sizes from three different batches of NC5, NC6 and NC5-PEG capsules are presented in Table 1. Moreover, the size of nanocapsules visualized by the cryo-Scanning Electron Microscopy was in good agreement with the values obtained by dynamic light scattering, as can be seen in Figure 1C. The particle concentration as determined by Nanoparticle Tracking Analysis was $\sim 2 \times 10^{12} / \mathrm{mL}$. Stability studies of the nanocapsules (in $15 \mathrm{mM} \mathrm{NaCl}, 25^{\circ} \mathrm{C}$ ) indicated no significant changes in their size and zeta potential during the period of 60 days.

\section{Negatively charged and PEGylated nanocapsules are not toxic for human RBCs and PBMCs}

Numerous nanoparticle types were found to interact with various blood components (erythrocytes, leukocytes, platelets or plasma proteins), which led to toxicity manifestations, such as hemolysis, blood coagulation or secretion of proinflammatory mediators. ${ }^{24,25}$ Thus, the first experiments were set to examine the influence of each type of tested polyelectrolyte nanocapsules on the viability of human PBMCs and erythrocytes. PBMCs 

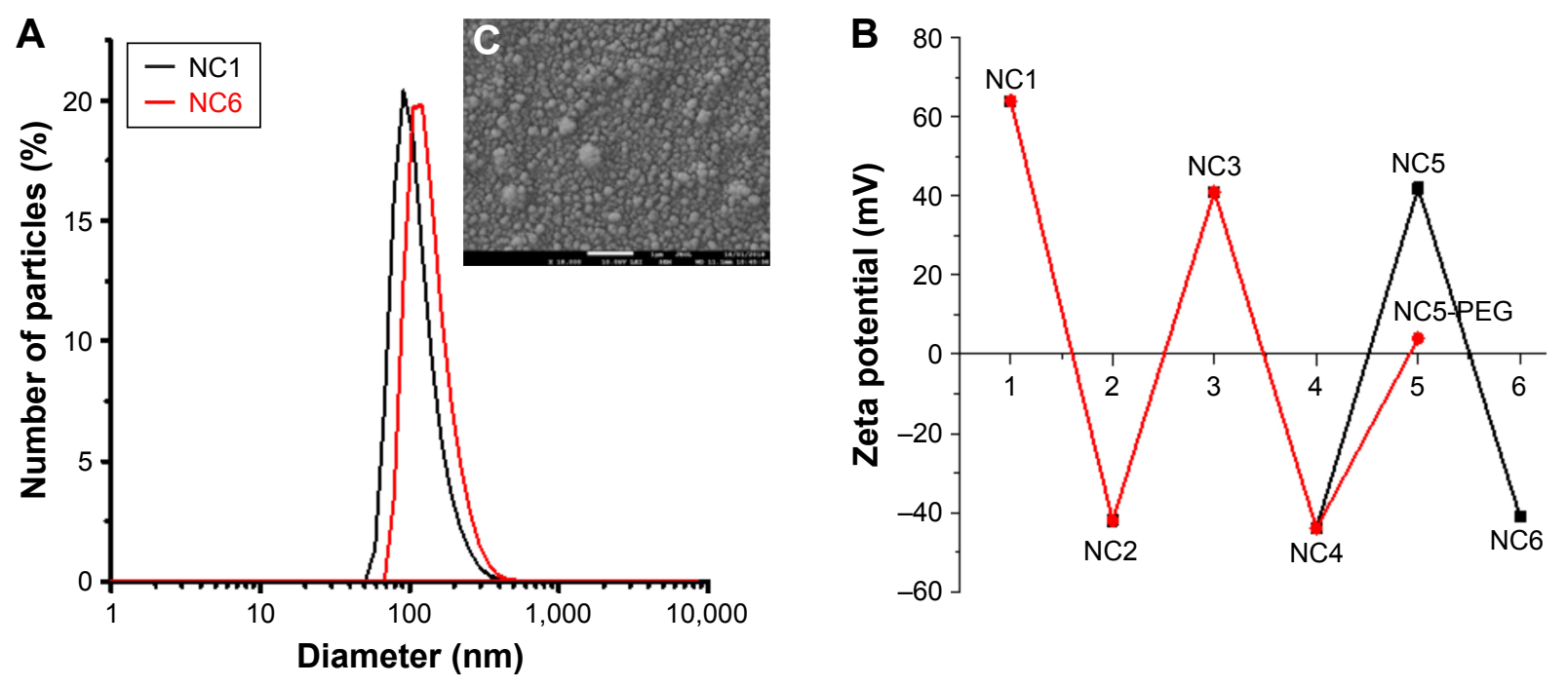

Figure I Characterization of polyelectrolyte nanocapsules used in this study.

Notes: (A) An example of size distribution of NCI-NC6 and NC5-PEG measured by DLS. (B) The dependence of zeta potential of nanocapsules on a number of layers in the polyelectrolyte shell. (C) The cryo-SEM micrograph of six-layer nanocapsules. Representative data for two different nanocapsule preparations used in this study.

Abbreviations: DLS, dynamic light scattering; NCI, nanoemulsion droplets; NC2, two-layer nanocapsules; NC3, three-layer nanocapsules; NC4, four-layer nanocapsules; NC5, five-layer nanocapsules; NC5-PEG, five-layer PEGylated nanocapsules; NC6, six-layer nanocapsules; SEM, scanning electron microscopy.

isolated from healthy adult donors were exposed to NC5, NC6 and NC5-PEG for 48 hours, and then, the number of dead cells was determined by trypan blue exclusion test. We observed a relatively high percentage $(25 \%)$ of dead cells in the control sample, probably due to freeze-thaw procedure. In contrast to NC6 or NC5-PEG, which did not affect cell viability, positively charged PLL-terminated NC5 exerted strong cytotoxicity against human PBMCs, increasing the number of dead cells to $61 \%$ (Figure 2A). The cytotoxic effect of NC5 was accompanied by $\mathrm{PBMC}$ aggregation. Interestingly, negatively charged PGA-terminated NC6 induced significant changes in the morphology of a subpopulation of PBMC. The observed changes in morphology are typical for monocytes that undergo phagocytosis and, most probably, the subpopulation includes nanocapsule-loaded monocytes. In contrast, PEGylated nanocapsules had no influence on PBMC morphology.

Similar to the results with PBMCs, only NC5 showed significant cytotoxicity toward erythrocytes in hemolytic assay.

Table I The average size from three different batches of $\mathrm{NCl}$ (PLL-terminated, one polyelectrolyte layer nanocapsules), NC5, NC6 and NC5-PEG

\begin{tabular}{ll}
\hline Nanocapsules & Size $(\mathbf{n m})$ \\
\hline NCI & $100 \pm 10$ \\
NC5 & $110 \pm 15$ \\
NC6 & $115 \pm 15$ \\
NC5-PEG & $125 \pm 10$ \\
\hline
\end{tabular}

Note: Data are presented as mean $\pm S D$.

Abbreviations: $\mathrm{NCl}$, nanoemulsion droplets; $\mathrm{NC5}$, five-layer nanocapsules; NC5-PEG, five-layer PEGylated nanocapsules; NC6, six-layer nanocapsules; PEG, polyethylene glycol; PLL, poly-L-lysine.
As presented in Figure 2B, after 3 hours of exposure of erythrocytes to $\mathrm{NC} 5$, the cells became aggregated and $>10 \%$ of hemoglobin was released; according to Dobrovolskaia and McNeil, ${ }^{26}$ negligible amounts of hemoglobin $(<2 \%)$ were released in response to NC6 and NC5-PEG.

Due to significant cytotoxicity of positively charged NC5 used in the concentration $\sim 2 \times 10^{11} / \mathrm{mL}$, we excluded these nanocapsules from further studies.

\section{Polyelectrolyte nanocapsules do not induce proinflammatory response in vitro}

Monocytes, macrophages and endothelial cells are the most prominent cells in inflammation. Therefore, we evaluated the possible proinflammatory activity of polyelectrolyte nanocapsules using mouse monocyte-macrophage cell line P388D1 and mouse brain endothelial MBE cells.

First, we verified that neither NC6 nor NC5-PEG had any influence on the morphology and viability of P388D1 and MBE cells incubated for 48 hours with nanocapsules (Figures 3A and S1). The levels of NO produced by iNOS, the expression of which is triggered in response to proinflammatory factors, is a useful and easy-to-measure marker of inflammation. Efficient expression of iNOS requires two stimulators: LPS and IFN- $\gamma$ are the best pair for monocytes and macrophages, including P388D1, while TNF and IFN- $\gamma$ are the best pair for MBE cells. To evaluate whether tested nanocapsules may affect in any way (trigger, potentiate, inhibit) the expression of iNOS, we incubated P388D1 and MBE cells for 24 hours with 1) NC6 or NC5-PEG or 
A

PBMC viability

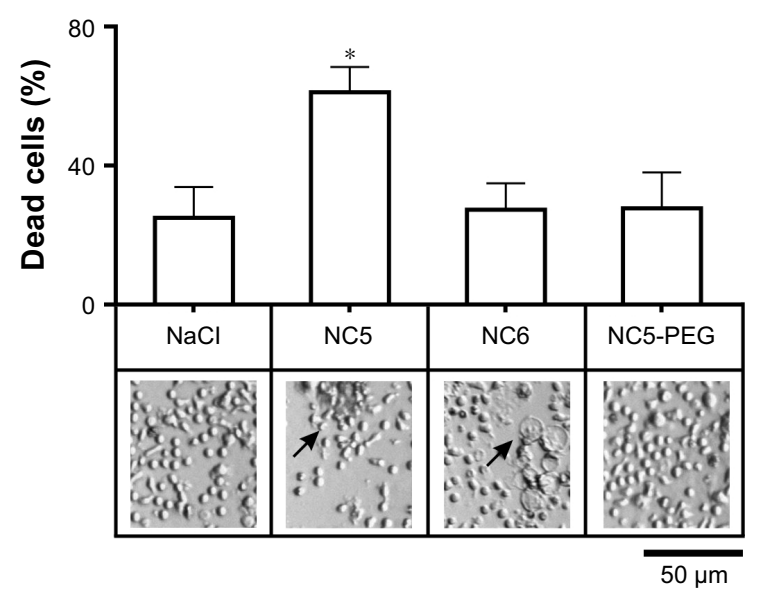

B

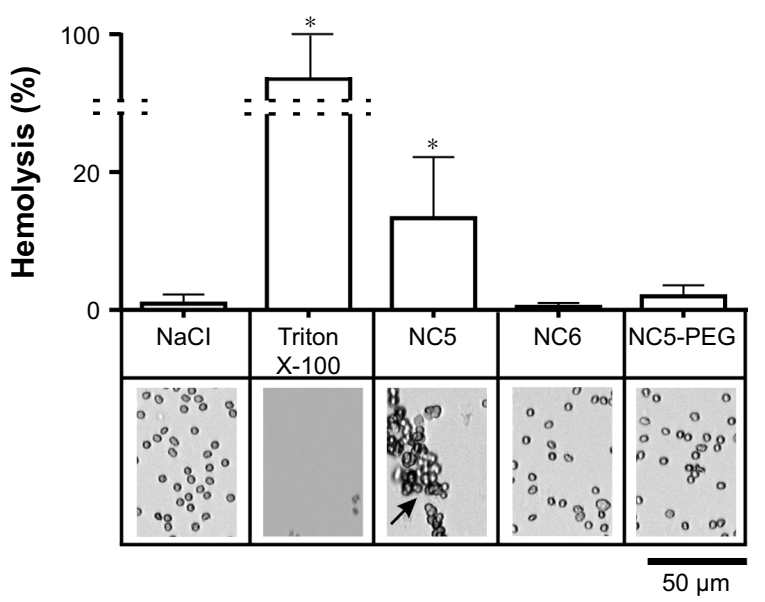

Figure 2 Analysis of the effect of polyelectrolyte nanocapsules on human PBMCs and erythrocytes.

Notes: (A) Viability of PBMCs. PBMCs were incubated for 48 hours with $1.5 \mathrm{mM} \mathrm{NaCl}$ or with different nanocapsules $\left(\sim 2 \times 10^{11} / \mathrm{mL}\right)$. All cells and dead cells were counted. (B) Detection of nanomaterial-induced hemolysis. RBCs were exposed for 3 hours to $1.5 \mathrm{mM} \mathrm{NaCl}$ or different nanocapsules or Triton X-I00. Detection of hemoglobin was performed spectrophotometrically. Morphological changes were analyzed using inverted light microscope. Arrows indicate cell aggregates or cells with changed morphology. $* P<0.05$.

Abbreviations: NC5, five-layer nanocapsules; NC5-PEG, five-layer PEGylated nanocapsules; NC6, six-layer nanocapsules; PBMC, peripheral blood mononuclear cell; PEG, polyethylene glycol; RBC, red blood cell.

2) a single iNOS stimulator or 3) a pair of stimulators in the absence or presence of tested nanomaterials, and measured the levels of nitrite (product of spontaneous NO oxidation) in cell culture media. We observed that nanocapsules neither induced production of NO by themselves nor enhanced the effect of single stimulators of iNOS transcription, that is, they did not provide the second proinflammatory signal (Figure 3B). They also did not affect the increased levels of NO produced by iNOS expressed in response to either pair of stimulators in P388D1 and MBE cells.

To confirm that the lack of effect of nanocapsules on inflammation is not limited to iNOS expression and NO synthesis, we also evaluated their possible impact on the expression of another marker of cytokine-mediated endothelial activation, namely VCAM-1. Flow cytometry analysis showed that, in contrast to TNF, a strong stimulator of VCAM-1 expression, neither NC6 nor NC5PEG was able to stimulate VCAM-1 expression in MBE cells over the basal level (Figure 3C).

\section{Oxidative stress is not observed in HepG2 cells exposed to polyelectrolyte nanocapsules}

Generation of ROS resulting in oxidative stress is one of the well-characterized mechanisms of nanomaterial toxicity. We analyzed the possible effect of polyelectrolyte nanocapsules on ROS formation in HepG2 cell line, which is a suitable model for the detection of oxidative stress induced by different agents including nanomaterials. ${ }^{27}$
After verifying that NC6 and NC5-PEG did not affect HepG2 morphology or viability (Figures 4A and S1), we estimated the levels of ROS generation in HepG2 using DCFH-DA assay. HepG2 cells were exposed to $\mathrm{NaCl}$ or nanocapsules for 2, 6 or 24 hours and then stained with DCFH-DA. After staining, the HepG2 cells were also exposed to $\mathrm{PBS}$ or $\mathrm{H}_{2} \mathrm{O}_{2}$ for 30 minutes. This approach allows not only the analysis of nanomaterial-mediated ROS formation, but also the verification of whether nanocapsules affect normal cellular response to ROS by inhibiting or stimulating antioxidative enzyme activity.

However, neither basal nor increased, via $\mathrm{H}_{2} \mathrm{O}_{2}$, levels of ROS were affected by 2-, 6- or 24-hour incubation of HepG2 cells with NC6 or NC5-PEG nanocapsules (Figure 4B). The lack of induction of oxidative stress by the nanomaterials was also confirmed by zymographic analysis of the activity of antioxidant enzyme, SOD. Mitochondrial manganese SOD (Mn-SOD) is a major ROS-scavenging enzyme in the cell. Therefore, upregulated expression and activity of Mn-SOD may be used as a very sensitive indicator of intracellular ROS. ${ }^{28}$ Unlike PMA, a known activator of Mn-SOD expression, neither NC6 nor NC5-PEG influenced Mn-SOD activity in HepG2 cells (Figure 4C).

\section{Polyelectrolyte nanocapsules are not genotoxic}

Finally, we analyzed potential genotoxicity of polyelectrolyte nanocapsules. We measured the levels of DNA damage in PBMC, P388D1 and HepG2 cells cultured for 2, 24 or 

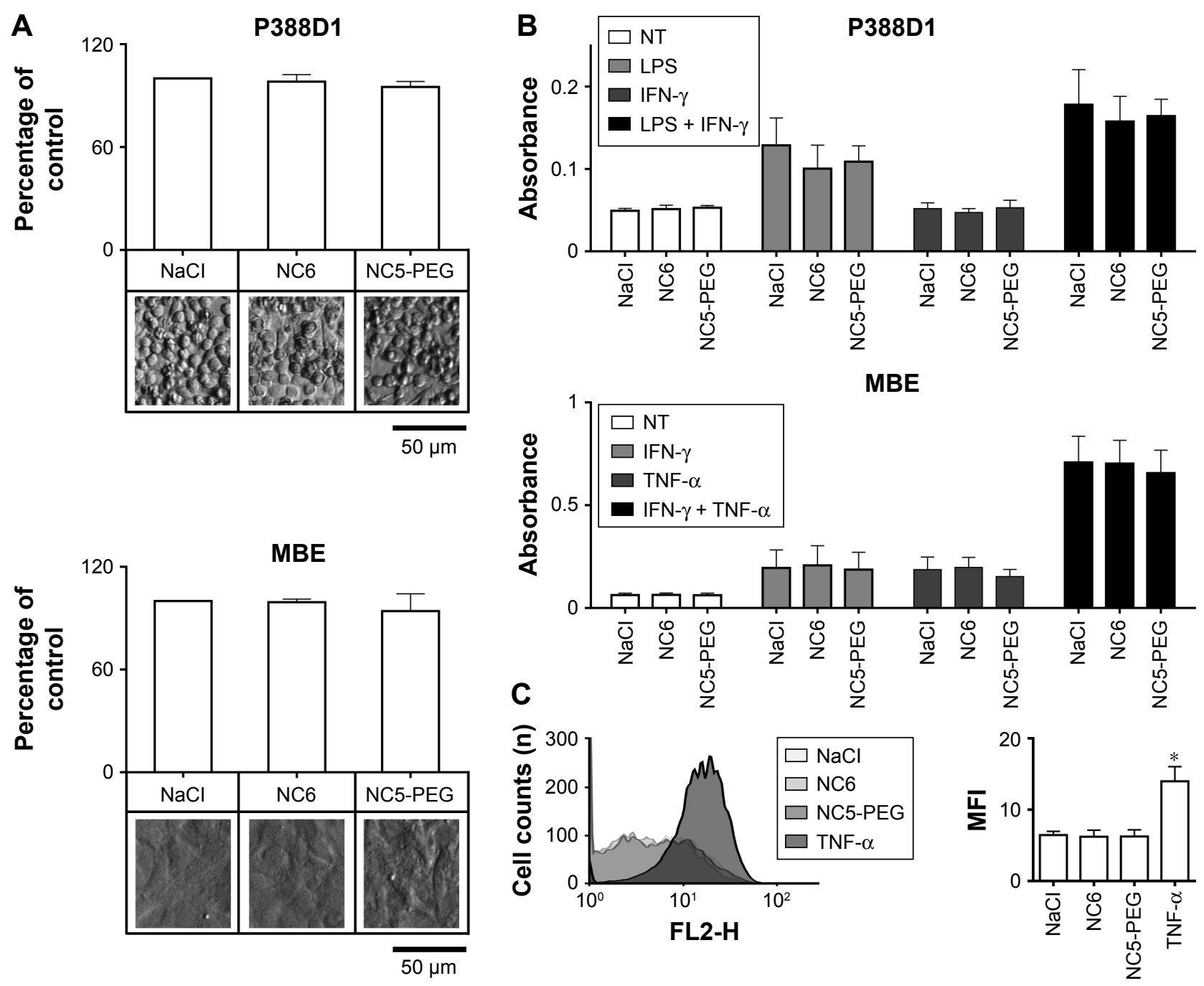

Figure 3 Analysis of inflammatory response to nanocapsules.

Notes: (A) Viability of mouse macrophage cell line P388DI and endothelial MBE cells. The cells were incubated for 48 hours in growth medium with I.5 mM NaCl or nanocapsules $\left(2 \times 10^{11} / \mathrm{mL}\right)$. (B) Analysis of NO production by iNOS. Nitrite levels were measured by Griess reaction after 24 hours incubation of the cells with I) nanocapsules or $\mathrm{NaCl}$ (NT), 2) LPS or cytokines and 3) nanocapsules and LPS or cytokines. (C) Flow cytometry analysis of VCAM-I expression on MBE cells. MBE cells were incubated for 24 hours with nanocapsules or with TNF and then stained with anti-VCAM-I antibody. $* P<0.05$

Abbreviations: LPS, lipopolysaccharide; MFI, mean fluorescence intensity; NC5-PEG, five-layer PEGylated nanocapsules; NC6, six-layer nanocapsules; NO, nitric oxide; PEG, polyethylene glycol; TNF, tumor necrosis factor; VCAM, vascular cell adhesion molecule.

48 hours in the presence or absence of nanocapsules, NC6 or NC5-PEG. Etoposide, a known DNA damage-inducing agent, was used as positive control. DNA strand breaks were measured after agarose gel electrophoresis of single cells. In contrast to etoposide, neither NC6 nor NC5-PEG increased the levels of DNA damage in any cell type and after any incubation period, strongly suggesting that the nanocapsules are not genotoxic (Figure 5).

\section{Discussion}

Intravenous administration is one of the most common routes of nanomaterial delivery. Thus, evaluation of the interplay between nanoparticles and blood components is considered as an important step in the development of nanomaterial drug carriers. Numerous reports indicated that different nanoparticles tend to directly interact with blood proteins and cells and may thus induce acute toxicity manifesting primarily in hemolysis, platelet aggregation, or severe proinflammatory response leading in extreme cases to serious, life-threatening events. ${ }^{29}$

Of all the polyelectrolyte nanocapsules tested for blood compatibility, only cationic PLL-terminated NC5 showed acute toxicity toward blood cells. They induced aggregation of both RBCs and PBMCs; aggregation of RBCs was accompanied by substantial hemolysis. We believe that, similar to the observations of Ziemba et al, the hemolytic activity of positively charged NC5 results from direct interaction with erythrocytes, which, due to a high surface expression 
A

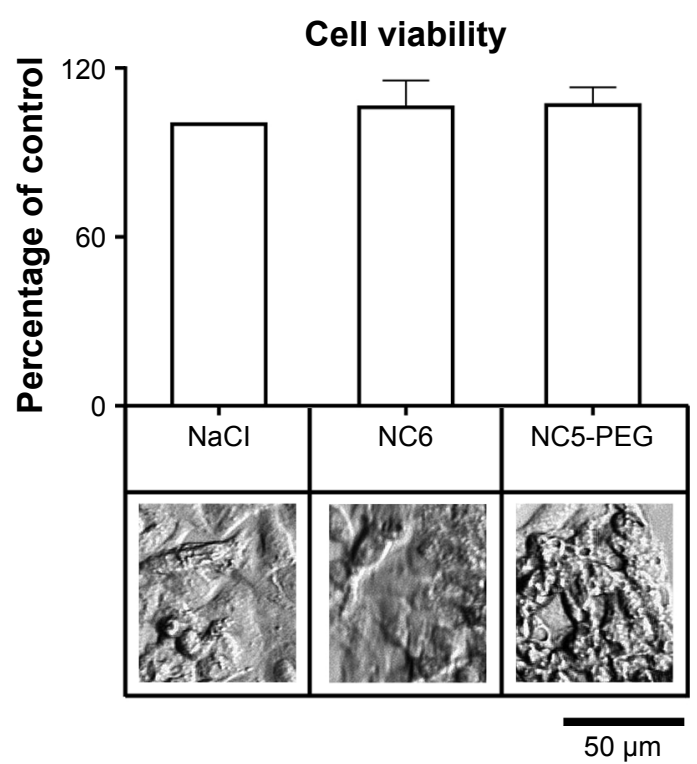

C

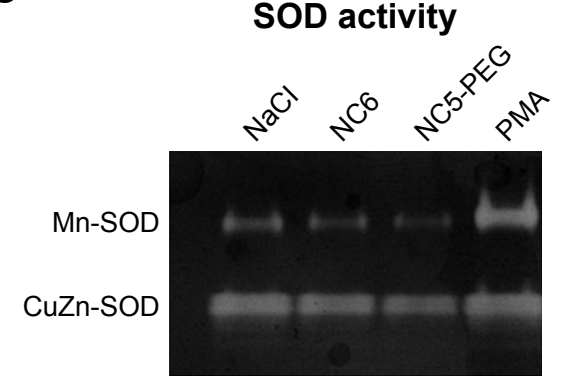

B

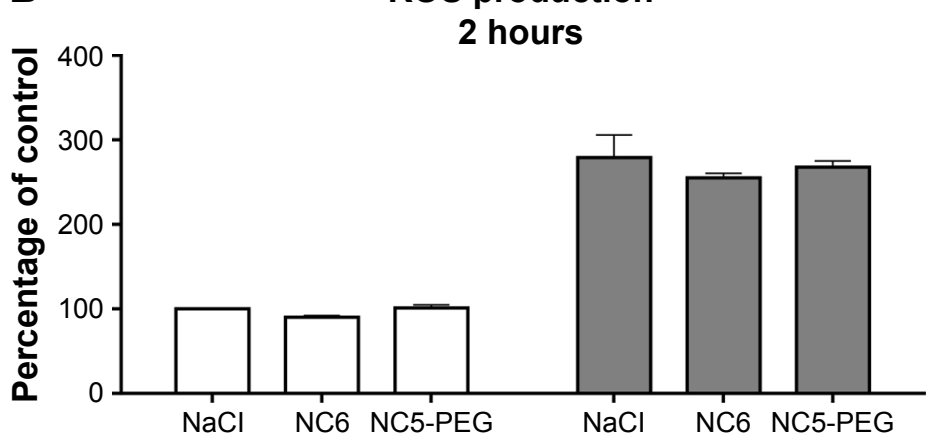

6 hours

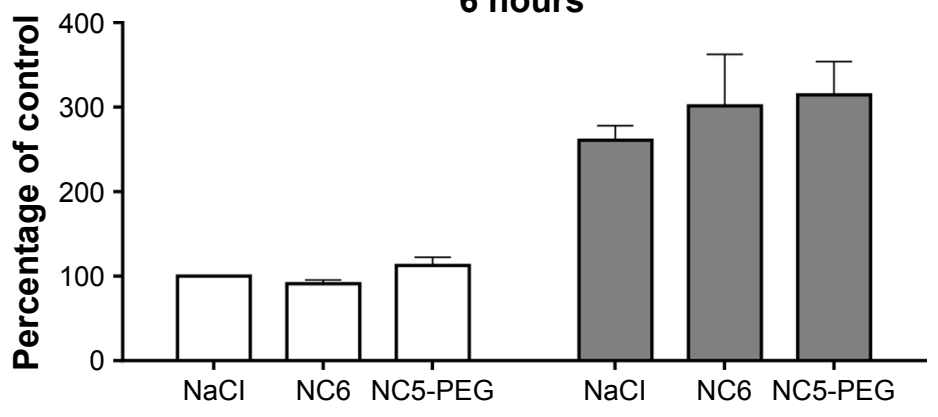

24 hours

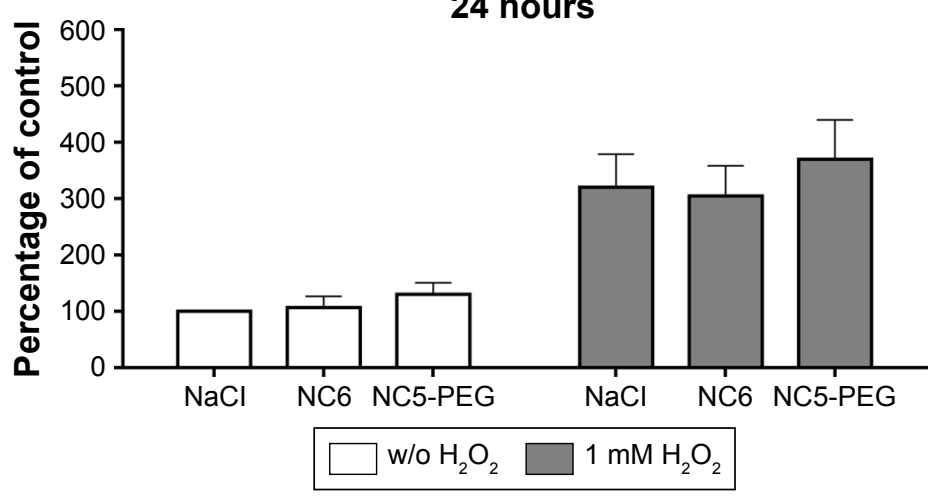

Figure 4 Analysis of potential nanoparticle-mediated oxidative stress.

Notes: (A) Viability of human hepatocellular cell line HepG2. Cells were exposed to nanocapsules for 48 hours. (B) Analysis of ROS generation. HepG2 cells were grown for 2,6 or 24 hours in media containing $1.5 \mathrm{mM} \mathrm{NaCl}$ or nanocapsules. Intracellular ROS were measured after staining the cells with DCFH-DA (white bars) or with DCFH-DA followed by incubation with I $\mathrm{mM} \mathrm{H}_{2} \mathrm{O}_{2}$ (gray bars). (C) Analysis of SOD activity by native PAGE-based zymography. HepG2 cells were exposed to nanocapsules or PMA. The upper band corresponds to ROS-inducible Mn-SOD activity and the lower band to the activity of constitutively expressed CuZn-SOD. The representative zymogram of three independent experiments performed is shown. Concentration of nanocapsules in these experiments was $\sim 2 \times 10^{11} / \mathrm{mL}$.

Abbreviations: DCFH-DA, 2'7'-dichlorofluorescin diacetate; NC5-PEG, five-layer PEGylated nanocapsules; NC6, six-layer nanocapsules; PAGE, polyacrylamide gel electrophoresis; PEG, polyethylene glycol; PMA, phorbol I2-myristate I3-acetate; ROS, reactive oxygen species; SOD, superoxide dismutase; w/o, without.

of glycoproteins and glycolipids rich in sialic acid, display strong negative charge resulting in electrostatic repulsion between cells. ${ }^{30}$ Thus, cationic nanomaterials interacting with erythrocyte surface may induce hemorheological alterations, aggregation and membrane destabilization, which leads to cell rupture and hemoglobin release. ${ }^{31}$ The charge-directed interactions of NC5 with PBMCs may also explain the aggregation and diminished viability of the cells. It is worth noting that NC5 was not toxic to P388D1, MBE and HepG2 cells (data not shown). Although our results indicate that cationic
NC5 used in the concentration $\sim 2 \times 10^{11} / \mathrm{mL}$ exhibited strong cytotoxicity against human blood cells, there are in vivo studies demonstrating that cationic nanomaterials composed of PLL but used in a lower concentration are safe and may be considered as promising nanomaterials with medical relevance. For example, Al-Jamal et al showed that cationic PLL dendrimers used to inhibit tumor vascularization or to deliver doxorubicin had safe toxicological profile in mouse models of cancer. ${ }^{32,33}$ Similarly, Ayyappan et al performed detailed toxicity studies of PLL nanocapsules in rats, 

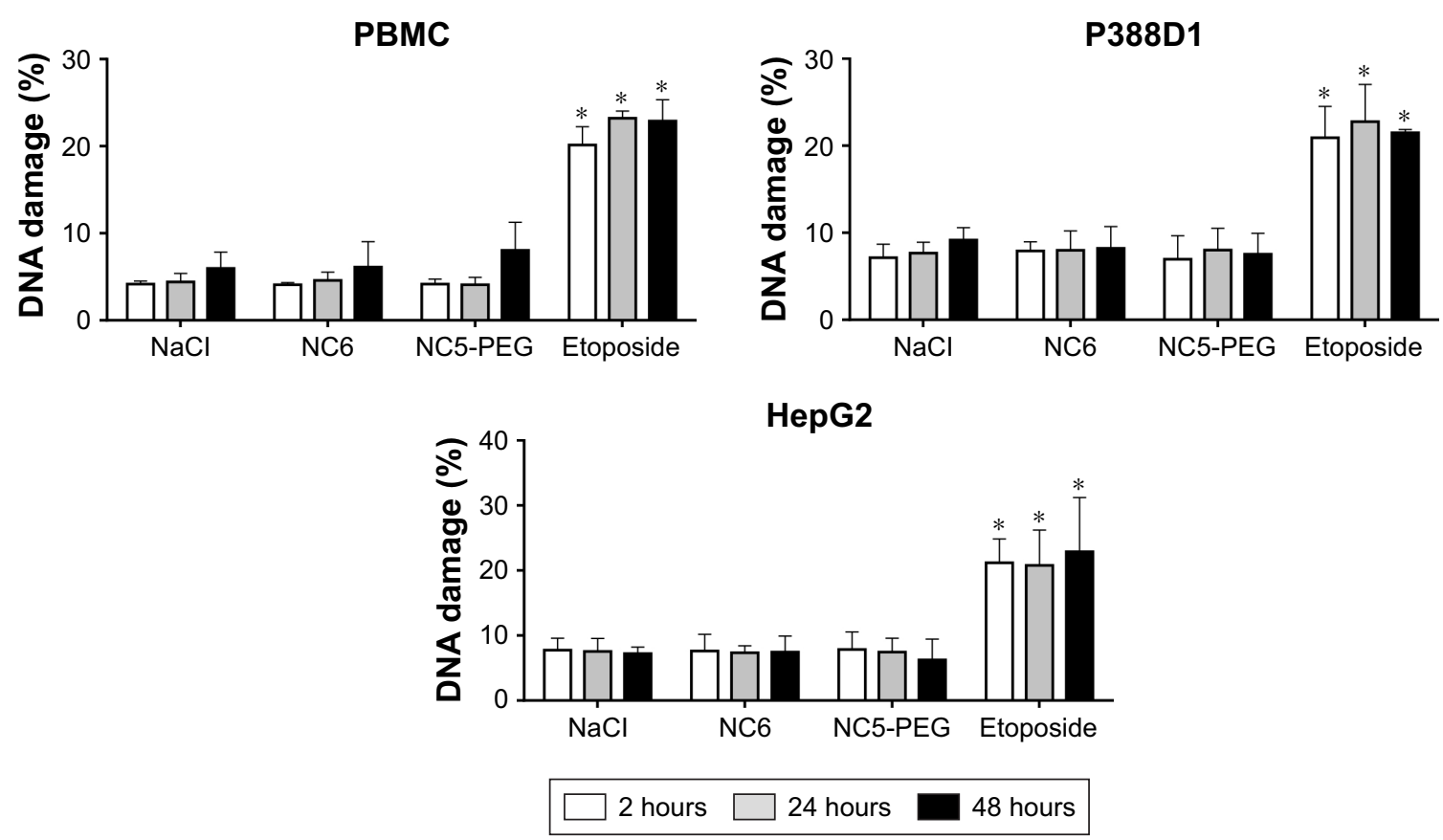

Figure 5 Quantification of DNA breaks after exposure of PBMC, P388DI and HepG2 cells to nanocapsules - comet assay. The cells were cultured for 2,24 or 48 hours in media containing $1.5 \mathrm{mM} \mathrm{NaCl}$ or nanocapsules $\left(\sim 2 \times 10^{11} / \mathrm{mL}\right)$ or etoposide. $* P<0.05$.

Abbreviations: NC5-PEG, five-layer PEGylated nanocapsules; NC6, six-layer nanocapsules; PBMC, peripheral blood mononuclear cell; PEG, polyethylene glycol.

demonstrating immunocompatibility and low toxicity of these nanocapsules. ${ }^{34}$

In contrast to $\mathrm{NC} 5$, negatively charged PGA-terminated NC6 did not cause RBC aggregation and hemolysis. However, although NC6 did not influence PBMC viability, it affected the morphology of monocytes within PBMC population, most probably by increased phagocytosis of the nanomaterial. This phenomenon was not observed for PEGylated NC5 and the difference may be significant when considering PGA as an alternative to PEG for decoration of nanocapsules' surface.

It was found that the efficiency of nanoparticles phagocytosis was correlated with their tendency to bind proteins. Thus, our present results are in agreement with those previously published which demonstrated that the interactions of nanocapsules with human serum albumin were strong for NC5, far weaker for NC6 and negligible for NC5-PEG, since it was shown that nanoparticles that strongly interact with proteins are more prone to phagocytosis. ${ }^{14,17}$ Decreased in vitro toxicity of PEGylated nanomaterials compared to unmodified ones, which may result from diminished uptake of PEGdecorated nanoparticles, has been demonstrated, for example, for PEGylated cationic liposome-DNA complexes..$^{35}$ On the other hand, PEG was shown to be immunogenic in mice and humans. The presence of anti-PEG antibodies in circulation may induce fast clearance of the nanomaterial and decrease its target tissue accumulation. Thus, application of other hydrophilic, non-immunogenic polymers, for example, PGA, for nanocapsules decoration could be the answer to the immunogenicity issue. PGA is an external layer of NC6. Although neither NC6 nor NC5-PEG showed any signs of cytotoxicity, NC6 had some influence on monocyte morphology. Only in vivo studies may verify which of the two nanocapsules are more suitable as drug carriers.

Data concerning the influence of biodegradable nanomaterials on PBMC and erythrocytes are scarce. Mendes et al observed that among different negatively charged polymeric nanomaterials (nanocapsules, nanospheres and liposomes), only nanostructured lipid carriers induced hemolysis of human red cells and decreased the viability of PBMCs. ${ }^{36}$ Our polycationic NC5 was not toxic toward several normal cell lines and its strong side effects were demonstrated only when its influence on erythrocytes and PBMCs was analyzed. The results clearly indicate the necessity to evaluate the impact of biodegradable nanomaterials on blood cells.

Proinflammatory activity of nanomaterials is another limiting factor in their clinical application. Nuclear factor- $\mathrm{kB}$ $(\mathrm{NF}-\kappa \mathrm{B})$, a transcription factor promptly activated by various inflammatory stimuli, plays a crucial role in the development of inflammation by stimulating the expression of proinflammatory factors including cytokines, adhesion molecules and iNOS. Changes in NF- $\mathrm{KB}$ activity in response 
to a nanomaterial are often regarded as an indicator of its influence on inflammatory response. To verify whether polyelectrolyte nanocapsules affect $\mathrm{NF}-\kappa \mathrm{B}$ activity, we analyzed the expression of two NF- $\mathrm{KB}$-dependent markers of inflammation, namely iNOS and VCAM-1. Measurement of nanomaterial-stimulated NO levels was already used to characterize the biological effects of some inorganic particles. For example, Hassanpour et al demonstrated that nanosilver colloid upregulates NO synthesis in different cell types. ${ }^{37}$ This phenomenon may arise from activation of p38 mitogen-activated protein kinase ${ }^{38}$ or increased levels of ROS generated in cells exposed to nanomaterial. Thus, impaired redox balance may obviously lead to the activation of NF- $\kappa B .{ }^{39}$ Moreover, the generation of high levels of NO, followed by the rapid production of other reactive nitrogen species, which are the major components of oxidative stress, is often considered as an essential mechanism of nanomaterial toxicity. ${ }^{40}$ Prolonged or excessive NO production has deleterious effects leading, among others, to serious endothelial dysfunction. Interestingly, certain nanoparticles composed of cerium oxide, obtained by Selvaraj et al, attenuated iNOS expression induced by LPS. ${ }^{41}$ Also, Ma et al observed that exposing mouse macrophage cell line RAW264.7 to gold nanoparticles led to downregulation of LPS-induced iNOS expression by inhibition of both $\mathrm{NF}-\kappa \mathrm{B}$ activation and IFN- $\beta /$ STAT1 pathway. ${ }^{42}$ If the NO synthesis is attenuated, the eradication of pathogens may be affected.

We demonstrated that NC6 and NC5-PEG applied to the tested cells neither induced iNOS-mediated NO synthesis nor influenced the levels of NO produced in response to LPS or cytokines. They also did not induce VCAM-1 expression on MBE. Endothelial cells, next to RBC and leukocytes, are the first to encounter a nanomaterial after its intravenous administration. Therefore, decreased cell viability or activation of endothelium after contact with nanocapsules may provoke proinflammatory events. VCAM-1 participates in inflammatory response by facilitating migration of immune cells to the subintimal space. Some nanoparticles, that is, silica nanomaterials, were found to upregulate endothelial expression of VCAM-1 and other adhesion molecules, increasing the risk of development of cardiovascular diseases. ${ }^{43}$

Although we did not determine NF- $\mathrm{\kappa B}$ activation directly, the lack of influence of tested nanomaterials on the expression of two distinct NF- $\mathrm{KB}$-dependent genes indicates that polyelectrolyte nanocapsules do not affect this transcription factor-mediated inflammatory response.

The toxic effect of numerous nanomaterials is often attributed to the generation of ROS followed by subsequent perturbations in intracellular signaling and damage of cell membrane and DNA that may lead to inflammation or carcinogenesis. The mechanism of nanomaterial-induced ROS formation may be governed by chemical or physical properties of the nanoparticles. For metallic nanomaterials, HaberWeiss and Fenton reactions are pointed as the main sources of ROS, whereas other nanoparticles, including biodegradable ones, may lead to oxidative stress by influencing the mitochondrial oxidative chain, membrane NADPH oxidase or by attenuating the activity of antioxidative enzymes. ${ }^{44,45}$ There are also reports on biodegradable nanoparticles, such as those composed of polyoxalate or poly(epsilon-caprolactone), that do not induce ROS formation. ${ }^{46}$

The liver plays an important role in nanomaterial sequestration from the blood circulation, followed by its accumulation and degradation. The generation of ROS is indicated as a predominant mechanism of nanomaterial hepatotoxicity. Thus, to evaluate polyelectrolyte nanocapsule-induced oxidative stress, we used the cell line originating from human hepatocytes, HepG2. Both direct assay, which measures ROS concentrations in the cells, and indirect assay evaluating ROS-induced expression of antioxidative enzymes showed that NC6 and NC5-PEG neither stimulated ROS formation in HepG2 cells nor affected the antioxidant response.

Nanomaterial-induced oxidative DNA damage has already been demonstrated in numerous studies, and oxidative stress is considered as a major mechanism of nanomaterial genotoxicity. Therefore, in the light of the above results, it is not surprising that polyelectrolyte nanocapsules did not induce DNA damage in either tested cells. However, a direct measurement of DNA damage as an element of nanomaterial testing is highly justified because, as shown by Zijno et al, some nanomaterials may potentiate DNA lesions by disturbing DNA repair machinery. ${ }^{47}$ We may classify PGAterminated NC6 and NC5-PEG to a group of non-genotoxic nanoparticles comprising other biodegradable nanomaterials such as biodegradable poly( $\varepsilon$-caprolactone) lipid-core nanocapsules. ${ }^{48}$ However, it must be stressed that certain biodegradable nanomaterials may induce DNA damage, ${ }^{49}$ thus, genotoxicity must be evaluated for all new biodegradable, potentially pharmaceutical, nanomaterials.

\section{Conclusion}

Our studies showed that two out of three analyzed biodegradable polyelectrolyte nanocapsules, negatively charged, six-layer nanocapsules with an external layer composed of PGA (NC6) and close-to-neutral, five-layer nanocapsules with an external layer composed of the copolymer of PLL and 
PEG (NC5-PEG), passed all in vitro quality assessments and are thus regarded suitable for in vivo testing as potential drug carriers. The nanomaterials neither affected the integrity of erythrocytes nor promoted the aggregation of PBMCs. They also did not 1) affect the viability of any tested cells, including PBMCs, P388D1, MBE, HepG2; 2) stimulate inflammatory response; 3 ) stimulate the formation of ROS, or affect the activity of antioxidant enzymes or 4) show any genotoxicity. Positively charged, PLL-terminated, five-layer nanocapsules (NC5) tested at a concentration of $\sim 2 \times 10^{11} / \mathrm{mL}$ were classified by us as toxic in vitro due to the strong interaction with human red blood cells and PBMCs.

Biodegradable nanoparticles are often considered safe and are passed for in vivo testing without prior appropriate in vitro analyses. The in vitro evaluation is often limited to examining their effects on the viability of established cell lines. We would like our work to set "a golden standard" for testing biocompatible materials, which in our opinion should include analyses of their influence on blood cells, ROS formation, activation of immune response and genotoxicity.

\section{Acknowledgments}

This work was supported by the Diamond Grant number 0014/DIA/2014/43 to AK, funded by the Polish Ministry of Science and Higher Education.

The Faculty of Biochemistry, Biophysics and Biotechnology of the Jagiellonian University in Kraków and the Jerzy Haber Institute of Catalysis and Surface Chemistry Polish Academy of Sciences are partners of the Leading National Research Center (KNOW) supported by the Polish Ministry of Science and Higher Education.

\section{Disclosure}

The authors report no conflicts of interest in this work.

\section{References}

1. Yildirimer L, Thanh NT, Loizidou M, Seifalian AM. Toxicology and clinical potential of nanoparticles. Nano Today. 2011;6(6):585-607.

2. Medintz IL, Mattoussi H, Clapp AR. Potential clinical applications of quantum dots. Int J Nanomedicine. 2008;3(2):151-167.

3. Wang K, Huang Q, Qiu F, Sui M. Non-viral delivery systems for the application in p53 cancer gene therapy. Curr Med Chem. 2015;22(35): 4118-4136.

4. Bobo D, Robinson KJ, Islam J, Thurecht KJ, Corrie SR. Nanoparticlebased medicines: a review of FDA-approved materials and clinical trials to date. Pharm Res. 2016;33(10):2373-2387.

5. Dobrovolskaia MA, Mcneil SE. Immunological properties of engineered nanomaterials. Nat Nanotechnol. 2007;2(8):469-478.

6. Gagliardi M. Novel biodegradable nanocarriers for enhanced drug delivery. Ther Deliv. 2016;7(12):809-826.

7. Gatoo MA, Naseem S, Arfat MY, Dar AM, Qasim K, Zubair S. Physicochemical properties of nanomaterials: implication in associated toxic manifestations. Biomed Res Int. 2014;2014:498420.
8. Hu CM, Fang RH, Luk BT, Zhang L. Polymeric nanotherapeutics: clinical development and advances in stealth functionalization strategies. Nanoscale. 2014;6(1):65-75.

9. Sukhorukov GB, Donath E, Lichtenfeld H, et al. Layer-by-layer self assembly of polyelectrolytes on colloidal particles. Colloids Surf A Physicochem Eng Asp. 1998;137(1-3):253-266.

10. Sarika PR, James NR. Polyelectrolyte complex nanoparticles from cationised gelatin and sodium alginate for curcumin delivery. Carbohydr Polym. 2016;148:354-361.

11. Zhang L, Wang J, Ni C, Zhang Y, Shi G. Preparation of polyelectrolyte complex nanoparticles of chitosan and poly(2-acrylamido-2methylpropanesulfonic acid) for doxorubicin release. Mater Sci Eng C Mater Biol Appl. 2016;58:724-729.

12. Parekh G, Pattekari P, Joshi C, et al. Layer-by-layer nanoencapsulation of camptothecin with improved activity. Int J Pharm. 2014;465(1-2): 218-227.

13. Lim C, Sim T, Hoang NH, et al. A charge-reversible nanocarrier using PEG-PLL (-g-Ce6, DMA)-PLA for photodynamic therapy. Int $J$ Nanomedicine. 2017;12:6185-6196.

14. Szczepanowicz K, Bzowska M, Kruk T, Karabasz A, Bereta J, Warszynski P. Pegylated polyelectrolyte nanoparticles containing paclitaxel as a promising candidate for drug carriers for passive targeting. Colloids Surf B Biointerfaces. 2016;143:463-471.

15. Ślusarczyk J, Piotrowski M, Szczepanowicz K, et al. Nanocapsules with polyelectrolyte shell as a platform for 1,25-dihydroxyvitamin D3 neuroprotection: study in organotypic hippocampal slices. Neurotox Res. 2016;30(4):581-592.

16. Łukasiewicz S, Szczepanowicz K. In vitro interaction of polyelectrolyte nanocapsules with model cells. Langmuir. 2014;30(4):1100-1107.

17. Łukasiewicz S, Szczepanowicz K, Błasiak E, Dziedzicka-Wasylewska M. Biocompatible polymeric nanoparticles as promising candidates for drug delivery. Langmuir. 2015;31(23):6415-6425.

18. Szczepanowicz K, Hoel HJ, Szyk-Warszynska L, et al. Formation of biocompatible nanocapsules with emulsion core and pegylated shell by polyelectrolyte multilayer adsorption. Langmuir. 2010;26(15):12592-12597.

19. Karabasz A, Bzowska M, Łukasiewicz S, Bereta J, Szczepanowicz K. Cytotoxic activity of paclitaxel incorporated into polyelectrolyte nanocapsules. J Nanopart Res. 2014;16:2340.

20. Dobrovolskaia MA, Clogston JD, Neun BW, Hall JB, Anil K, McNeil SE. Method for analysis of nanoparticle hemolytic properties in vitro. Nano Lett. 2009;8(8):2180-2187.

21. Celis J. Cell Biology: A Laboratory Handbook. 2nd ed. San Diego: Academic Press; 1998.

22. Kyzioł A, Cierniak A, Gubernator J, Markowski A, Jeżowska-Bojczuk M, Komarnicka UK. Copper(i) complexes with phosphine derived from sparfloxacin. Part III: multifaceted cell death and preliminary study of liposomal formulation of selected copper(i) complexes. Dalton Trans. 2018;47(6):1981-1992.

23. Szczepanowicz K, Dronka-Góra D, Para G, Warszyński P. Encapsulation of liquid cores by layer-by-layer adsorption of polyelectrolytes. J Microencapsul. 2010;27(3):198-204.

24. Janeesh PA, Sami H, Dhanya CR, Sivakumar S, Abraham A. Biocompatibility and genotoxicity studies of polyallylamine hydrochloride nanocapsules in rats. RSC Adv. 2014;4(47):24484-24497.

25. Bhattacharya K, Kiliç G, Costa PM, Fadeel B. Cytotoxicity screening and cytokine profiling of nineteen nanomaterials enables hazard ranking and grouping based on inflammogenic potential. Nanotoxicology. 2017; 11(6):809-826.

26. Dobrovolskaia MA, McNeil SE. Understanding the correlation between in vitro and in vivo immunotoxicity tests for nanomedicines. $J$ Control Release. 2013;172(2):456-466.

27. Yuan J, Gao H, Sui J, Duan H, Chen WN, Ching CB. Cytotoxicity evaluation of oxidized single-walled carbon nanotubes and graphene oxide on human hepatoma HepG2 cells: an iTRAQ-coupled 2D LC-MS/ MS proteome analysis. Toxicol Sci. 2012;126(1):149-161.

28. Holley AK, Bakthavatchalu V, Velez-Roman JM, St Clair DK. Manganese superoxide dismutase: guardian of the powerhouse. Int J Mol Sci. 2011;12(10):7114-7162. 
29. Nemmar A, Al-Salam S, Beegam S, Yuvaraju P, Ali BH. The acute pulmonary and thrombotic effects of cerium oxide nanoparticles after intratracheal instillation in mice. Int J Nanomedicine. 2017;12: 2913-2922.

30. Ziemba B, Matuszko G, Bryszewska M, Klajnert B. Influence of dendrimers on red blood cells. Cell Mol Biol Lett. 2012;17(1):21-35.

31. Neu B, Meiselman HJ. Depletion-mediated red blood cell aggregation in polymer solutions. Biophys J. 2002;83(5):2482-2490.

32. Al-Jamal KT, Al-Jamal WT, Wang JT, et al. Cationic poly-L-lysine dendrimer complexes doxorubicin and delays tumor growth in vitro and in vivo. ACS Nano. 2013;7(3):1905-1917.

33. Al-Jamal KT, Al-Jamal WT, Akerman S, et al. Systemic antiangiogenic activity of cationic poly-L-lysine dendrimer delays tumor growth. Proc Natl Acad Sci U S A. 2010;107(9):3966-3971.

34. Ayyappan JP, Sami H, Rajalekshmi DC, Sivakumar S, Abraham A. Immunocompatibility and toxicity studies of poly-L-lysine nanocapsules in Sprague Dawley rats for drug-delivery applications. Chem Biol Drug Des. 2014;84(3):292-299.

35. Eliyahu H, Servel N, Domb AJ, Barenholz Y. Lipoplex-induced hemagglutination: potential involvement in intravenous gene delivery. Gene Ther. 2002;9(13):850-858.

36. Mendes LP, Delgado JM, Costa AD, et al. Biodegradable nanoparticles designed for drug delivery: the number of nanoparticles impacts on cytotoxicity. Toxicol In Vitro. 2015;29(6):1268-1274

37. Hassanpour H, Mirshokraei P, Sadrabad EK, Khalili Sadrabad E, et al. In vitro effect of nanosilver on gene expression of superoxide dismutases and nitric oxide synthases in chicken Sertoli cells. Animal. 2015;9(2): 295-300.

38. Liu Z, Li W, Wang F, et al. Enhancement of lipopolysaccharide-induced nitric oxide and interleukin- 6 production by PEGylated gold nanoparticles in RAW264.7 cells. Nanoscale. 2012;4(22):7135.

39. Chang $X$, Zhu A, Liu F, et al. Role of NF- $\kappa B$ activation and Th1/Th2 imbalance in pulmonary toxicity induced by nano NiO. Environ Toxicol. 2017;32(4):1354-1362.
40. Kumar S, Meena R, Paulraj R. Role of macrophage (M1 and M2) in titanium-dioxide nanoparticle-induced oxidative stress and inflammatory response in rat. Appl Biochem Biotechnol. 2016;180(7):1257-1275.

41. Selvaraj V, Nepal N, Rogers S, et al. Inhibition of MAP kinase/NF-kB mediated signaling and attenuation of lipopolysaccharide induced severe sepsis by cerium oxide nanoparticles. Biomaterials. 2015;59:160-171.

42. Ma JS, Kim WJ, Kim JJ, et al. Gold nanoparticles attenuate LPS-induced NO production through the inhibition of NF-kappaB and IFN-beta/ STAT1 pathways in RAW264.7 cells. Nitric Oxide. 2010;23(3): 214-219.

43. Guo C, Xia Y, Niu P, et al. Silica nanoparticles induce oxidative stress, inflammation, and endothelial dysfunction in vitro via activation of the MAPK/Nrf2 pathway and nuclear factor- $\kappa \mathrm{B}$ signaling. Int J Nanomedicine. 2015;10(1):1463.

44. Fan J, Yin JJ, Ning B, et al. Direct evidence for catalase and peroxidase activities of ferritin-platinum nanoparticles. Biomaterials. 2011; 32(6):1611-1618

45. Fang GD, Zhou DM, Dionysiou DD. Superoxide mediated production of hydroxyl radicals by magnetite nanoparticles: demonstration in the degradation of 2-chlorobiphenyl. J Hazard Mater. 2013;250-251:68-75.

46. Yoo D, Guk K, Kim H, Khang G, Wu D, Lee D. Antioxidant polymeric nanoparticles as novel therapeutics for airway inflammatory diseases. Int J Pharm. 2013;450(1-2):87-94.

47. Zijno A, de Angelis I, de Berardis B, et al. Different mechanisms are involved in oxidative DNA damage and genotoxicity induction by $\mathrm{ZnO}$ and $\mathrm{TiO} 2$ nanoparticles in human colon carcinoma cells. Toxicol In Vitro. 2015;29(7):1503-1512.

48. Bulcão RP, de Freitas FA, Dallegrave E, et al. In vivo toxicological evaluation of polymeric nanocapsules after intradermal administration. Eur J Pharm Biopharm. 2014;86(2):167-177.

49. Platel A, Carpentier R, Becart E, Mordacq G, Betbeder D, Nesslany F Influence of the surface charge of PLGA nanoparticles on their in vitro genotoxicity, cytotoxicity, ROS production and endocytosis. J Appl Toxicol. 2016;36(3):434-444. 


\section{Supplementary material}
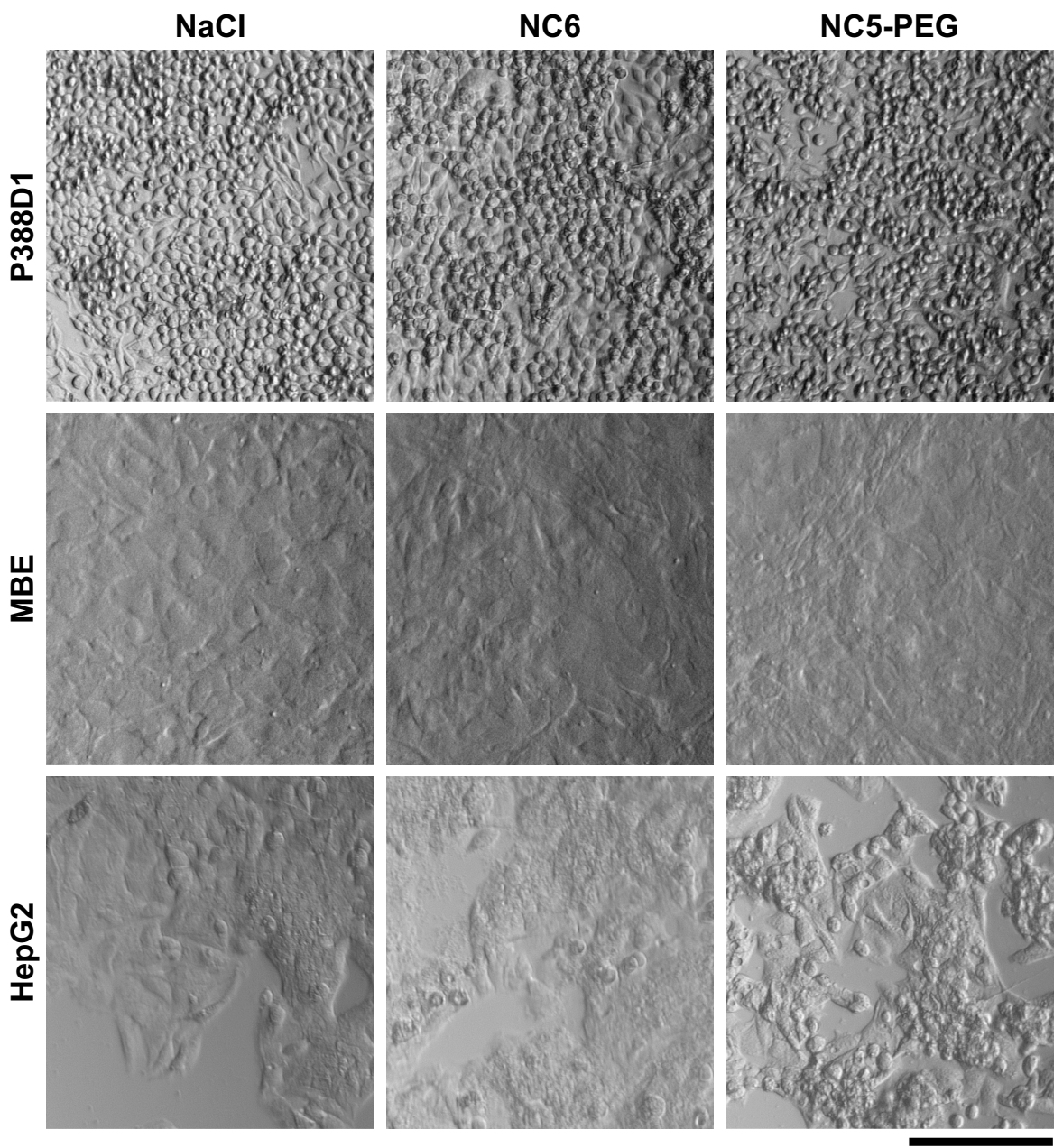

$50 \mu \mathrm{m}$

Figure SI Morphology of various cell lines exposed to nanocapsules for 48 hours.

Notes: The cells were grown for 48 hours in a medium containing $1.5 \mathrm{mM} \mathrm{NaCl}$ or nanocapsules $\left(\sim 2 \times 10^{11} / \mathrm{mL}\right)$. Morphological changes were analyzed using the inverted light microscope LeicaDM IL LED Fluo.

Abbreviations: NC5-PEG, five-layer PEGylated nanocapsules; NC6, six-layer nanocapsules; PEG, polyethylene glycol.

International Journal of Nanomedicine

\section{Publish your work in this journal}

The International Journal of Nanomedicine is an international, peerreviewed journal focusing on the application of nanotechnology in diagnostics, therapeutics, and drug delivery systems throughout the biomedical field. This journal is indexed on PubMed Central, MedLine, CAS, SciSearch ${ }^{\circledR}$, Current Contents $₫ /$ Clinical Medicine,

\section{Dovepress}

Journal Citation Reports/Science Edition, EMBase, Scopus and the Elsevier Bibliographic databases. The manuscript management system is completely online and includes a very quick and fair peer-review system, which is all easy to use. Visit http://www.dovepress.com/ testimonials.php to read real quotes from published authors. 